\title{
BMJ Open Are lifestyle pattern changes associated to poor subjective sleep quality?: a cross-sectional study by gender among the general Japanese population underwent specified medical check-ups in 2014 and 2015
}

\author{
Tomoo Hidaka (1D , ${ }^{1}$ Hideaki Kasuga (1D , ${ }^{1}$ Shota Endo, ${ }^{1}$ Yusuke Masuishi, ${ }^{1}$ \\ Takeyasu Kakamu (D) , ${ }^{1}$ Akiko Takeda, ${ }^{2}$ Makoto Koizumi, ${ }^{2}$ Tetsuhito Fukushima ${ }^{1}$
}

To cite: Hidaka T, Kasuga $\mathrm{H}$, Endo $\mathrm{S}$, et al. Are lifestyle pattern changes associated to poor subjective sleep quality?: a cross-sectional study by gender among the general Japanese population underwent specified medical check-ups in 2014 and 2015. BMJ Open 2020;10:e037613. doi:10.1136/ bmjopen-2020-037613

- Prepublication history for this paper is available online. To view these files, please visit the journal online (http://dx.doi. org/10.1136/bmjopen-2020037613).

Received 10 February 2020 Revised 10 November 2020 Accepted 17 November 2020

Check for updates

(c) Author(s) (or their employer(s)) 2020. Re-use permitted under CC BY-NC. No commercial re-use. See rights and permissions. Published by BMJ.

${ }^{1}$ Department of Hygiene and Preventive Medicine, Fukushima Medical University School of Medicine, Fukushima, Japan

${ }^{2}$ Fukushima National Health Insurance Organization,

Fukushima, Japan

Correspondence to

Mr Tomoo Hidaka;

thidaka@fmu.ac.jp

\section{ABSTRACT}

Objectives Subjective sleep quality (SSQ) is defined by the satisfaction of one's overall sleep experience and is composed of sleep depth and restfulness. It has not been clarified how poor SSQ is associated to changes in lifestyles. The purpose is to reveal the association of lifestyle pattern changes and poor SSQ.

Design A cross-sectional study.

Setting The data on basic attributes, SSQ and lifestyle such as presence/absence of smoking, exercise, physical activity, supper time close to bedtime, drinking habits and alcohol intake amount per day were obtained from database and questionnaire of specified medical checkups in fiscal year 2014-2015 in Japan. The analysis was conducted in 2019.

Participants The subjects comprised 49483 residents (26087 men and 23396 women), aged 40-74 years who had undergone an annual specified medical check-up from 2014 to 2015 in Fukushima Prefecture, Japan.

Outcome measure Status of SSQ in 2015 was assessed using a question asking whether or not the subjects usually got enough sleep. Poor SSQ in 2015 and lifestyle pattern changes in 2014-2015 were compared between those who were in healthy status both in 2014 and 2015 (referent) and non-referent, using binary logistic regression analysis.

Results Unhealthy lifestyle pattern for 2014-2015 was significantly associated to poor SSQ in 2015: 'absent to absent' in exercise for men ( $\mathrm{OR}=1.472 ; 95 \% \mathrm{Cl} 1.316$ to 1.647$)$ and women $(\mathrm{OR}=1.428 ; 95 \% \mathrm{Cl} 1.285$ to 1.587), physical activity for men $(0 \mathrm{R}=1.420 ; 95 \% \mathrm{Cl}$ 1.270 to 1.588$)$ and women $(\mathrm{OR}=1.471 ; 95 \% \mathrm{Cl} 1.322$ to 1.638) and 'present to present' in supper time for men $(\mathrm{OR}=1.149 ; 95 \% \mathrm{Cl} 1.020$ to 1.294$)$ and women (OR=1.288; $95 \% \mathrm{Cl} 1.102$ to 1.505$)$.

Conclusions Healthcare workers may be able to contribute to the improvement of SSQ, focusing on changeable lifestyles.

\section{INTRODUCTION}

Subjective sleep quality (SSQ) is defined by the satisfaction of one's overall sleep

\section{Strengths and limitations of this study}

- This study provides important insight into the association between lifestyle changes and subjective sleep quality, categorising such lifesyle changes for 2 years into four patterns, which were used for analysis.

- We employed a cross-sectional study design, instead of cohort, for the current research, because a cross-sectional study was considered to be more suitable than a cohort study in which the time of assessment of lifestyle and subjective sleep quality differs.

- A limitation of the current study was that the duration of lifestyle habits was not measured, and thus the answers in each year may not reflect the actual duration of the habits in question.

experience and is composed of sleep depth and restfulness. ${ }^{12}$ Past studies have reported poor SSQ to be associated with several health problems such as sleep apnoea ${ }^{3}$ depression, ${ }^{4}$ suicide, ${ }^{5}$ obesity $^{6}$ and cardiovascular disease. ${ }^{7}$ Sleep disturbance such as low-quality sleep may cause an increase in medical costs in cases where it accompanies other diseases. ${ }^{8}$ Thus, poor sleep quality is considered to be a growing public health problem in many countries.

Previous studies have demonstrated that poor SSQ is prevalent among individuals with unhealthy lifestyles, such as those with a lack of exercise and/or physical activity, ${ }^{9} 10$ those who smoke ${ }^{11}$ and/or engage in binge drinking ${ }^{12}$ and those who eat meals close to bedtime. ${ }^{13}$

However, it has not been clarified how SSQ is associated to changes in such lifestyles. 


\begin{tabular}{|c|c|c|}
\hline Variables & 2014 & 2015 \\
\hline \multicolumn{3}{|l|}{ Gender } \\
\hline Male & - & $26087(52.7)$ \\
\hline Female & - & $23396(47.3)$ \\
\hline $\begin{array}{l}\text { Age (years), median (25-75 } \\
\text { percentile) }\end{array}$ & - & $68(64-72)$ \\
\hline $40-49$ & - & 1790 (3.6) \\
\hline $50-59$ & - & $4639(9.4)$ \\
\hline $60-69$ & - & $24718(50)$ \\
\hline $70-74$ & - & $18336(37.1)$ \\
\hline $\mathrm{BM} \pm \mathrm{SD}$ & $23.4 \pm 3.2$ & $23.4 \pm 3.3$ \\
\hline Underweight $(<18.5)$ & $2255(4.6)$ & $2362(4.8)$ \\
\hline Normal $(\geq 18.5$ and $<25)$ & $33194(67.1)$ & $33014(66.7)$ \\
\hline Overweight $(\geq 25)$ & $14034(28.4)$ & $14107(28.5)$ \\
\hline \multicolumn{3}{|l|}{ Hypertension } \\
\hline Normal & $11342(22.9)$ & $11017(22.3)$ \\
\hline Elevated & 9366 (18.9) & 9564 (19.3) \\
\hline Stage 1 & $17319(35.0)$ & $17289(34.9)$ \\
\hline Stage 2 & $11456(23.2)$ & $11613(23.5)$ \\
\hline \multicolumn{3}{|l|}{ Diabetes } \\
\hline Present & 4526 (9.1) & 4933 (10) \\
\hline Absent & $44957(90.9)$ & $44550(90)$ \\
\hline \multicolumn{3}{|l|}{ Smoking } \\
\hline Present & $7106(14.4)$ & 6879 (13.9) \\
\hline Absent & $42377(85.6)$ & $42604(86.1)$ \\
\hline \multicolumn{3}{|l|}{ Exercise } \\
\hline Present & $21518(43.5)$ & $21595(43.6)$ \\
\hline Absent & $27965(56.5)$ & $27888(56.4)$ \\
\hline \multicolumn{3}{|l|}{ Physical activity } \\
\hline Present & $22646(45.8)$ & $22470(45.4)$ \\
\hline Absent & 26837 (54.2) & $27013(54.6)$ \\
\hline
\end{tabular}

Supper time close to bedtime

\begin{tabular}{|c|c|c|}
\hline Present & 8028 (16.2) & 7736 (15.6) \\
\hline Absent & $41455(83.8)$ & 41747 (84.4) \\
\hline \multicolumn{3}{|l|}{ Drinking habits } \\
\hline Every day & $17984(36.3)$ & $17670(35.7)$ \\
\hline Sometimes & $14793(29.9)$ & $14990(30.3)$ \\
\hline Rarely/cannot drink & $16706(33.8)$ & $16823(34.0)$ \\
\hline \multicolumn{3}{|c|}{$\begin{array}{l}\text { Alcohol intake amount per } \\
\text { day }\end{array}$} \\
\hline$<20 \mathrm{~g}$ & 31447 (63.6) & 31617 (63.9) \\
\hline $20-39 g$ & $12664(25.6)$ & $12755(25.8)$ \\
\hline $40-59 \mathrm{~g}$ & $4611(9.3)$ & $4360(8.8)$ \\
\hline$\geq 60 \mathrm{~g}$ & $761(1.5)$ & $751(1.5)$ \\
\hline
\end{tabular}

Continued

\begin{tabular}{cll|}
\hline Table 1 Continued & & \\
\hline Variables & $\mathbf{2 0 1 4}$ & $\mathbf{2 0 1 5}$ \\
\hline Present & - & $6069(12.3)$ \\
Absent & - & $43414(87.7)$ \\
\hline
\end{tabular}

Note: $\mathrm{n}(\%)$.

BMI, body mass index.

SSQ is fundamental to reports of insomnia and nonrestorative sleep, ${ }^{2}$ and thus it is important to understand the mechanism of poor SSQ in relation to such changes for improvement of major sleep problems such as insomnia and non-restorative sleep. Previous studies have reported that lifestyle changes such as smoking cessation, increased physical activity and healthy diet contribute to the reduction of the sleep problems such as insomnia, ${ }^{14}$ obstructive sleep apnoea, ${ }^{15}$ difficulty of falling asleep ${ }^{16}$ and shorter sleep time. ${ }^{17}$ Although these sleep problems are not directly equivalent to SSQ, above-mentioned past studies may suggest that the lifestyle changes possibly have important role on poor SSQ.

The purpose of the present study was to examine the association between lifestyle pattern changes and SSQ using 2-year longitudinal data. We hypothesised that poor SSQ is associated to unhealthy lifestyle changes or keeping unhealthy lifestyle such as starting/continuing smoking and supper time close to bedtime, increasing the frequency and volume of alcohol intake or keeping binge drinking or reducing the frequency/continuous absence of exercise and/or physical activity.

\section{METHODS}

\section{Study design and participants}

In this cross-sectional study, we used the data of 91795 residents, aged 40 to 74 years, who had undergone an annual specified medical check-up in all years from 2014 to 2015 in Fukushima Prefecture, Japan, by the National Health Insurance Organisation. Of 91795 residents, individuals who had poor SSQ in 2014 and whose data on age, gender, body mass index (BMI), blood pressure, fasting plasma glucose, haemoglobin A1C (HbAlc), habits of smoking, exercise, physical activity, eating meals close to bedtime, drinking (frequency and volume of alcohol intake) and sleep quality were incomplete and excluded from the present study. The analysis was conducted in 2019 , and the total number of participants was 49483 (26 087 men and 23396 women).

\section{Measurement}

The specified medical check-up included a questionnaire asking about lifestyles and SSQ. Together with the check-up data on basic attributes, the responses were recorded in the National Health Insurance Organisation's database and used for this study. 
Table 2 Associations of basic attribute and lifestyle transition with poor subjective sleep quality in 2015 among men

\begin{tabular}{|c|c|c|c|}
\hline \multirow[b]{3}{*}{ Variables } & \multicolumn{3}{|c|}{ Poor subjective sleep quality in 2015} \\
\hline & Present & Absent & \\
\hline & $(n=2949)$ & $(n=23138)$ & $P$ value \\
\hline Age (years), median (25-75 percentile) & $67(63-72)$ & $68(64-72)$ & $<0.001^{*}$ \\
\hline BMI & & & $0.003^{*}$ \\
\hline Normal to normal & $1824(11.4)$ & $14237(88.6)$ & \\
\hline Underweight/overweight to normal & $86(9.1) \ddagger$ & $854(90.9) \dagger$ & \\
\hline Underweight/normal/overweight to underweight & $101(15.1) \dagger$ & 569 (84.9)‡ & \\
\hline Underweight/normal/overweight to overweight & $938(11.1)$ & $7478(88.9)$ & \\
\hline Hypertension & & & $0.012^{*}$ \\
\hline Absent to absent & $674(11.7)$ & $5079(88.3)$ & \\
\hline Absent to present & 448 (11.9) & $3308(88.1)$ & \\
\hline Present to absent & $464(12.2) \dagger$ & $3328(87.8) \ddagger$ & \\
\hline Present to present & $1363(10.7) \ddagger$ & $11423(89.3) \dagger$ & \\
\hline Diabetes & & & 0.457 \\
\hline Absent to absent & $2522(11.4)$ & $19551(88.6)$ & \\
\hline Absent to present & $99(10.8)$ & $820(89.2)$ & \\
\hline Present to absent & $72(11.4)$ & $561(88.6)$ & \\
\hline Present to present & $256(10.4)$ & $2206(89.6)$ & \\
\hline Smoking & & & $0.027^{*}$ \\
\hline Absent to absent & $2195(11.1)$ & $17578(88.9)$ & \\
\hline Absent to present & 25 (10.3) & $218(89.7)$ & \\
\hline Present to absent & $67(15.3) \dagger$ & $371(84.7) \ddagger$ & \\
\hline Present to present & $662(11.8)$ & $4971(88.2)$ & \\
\hline Exercise & & & $<0.001^{*}$ \\
\hline Present to present & 718 (7.9)‡ & $8353(92.1) \dagger$ & \\
\hline Present to absent & $345(13.1) \dagger$ & $2282(86.9) \ddagger$ & \\
\hline Absent to present & $264(10.1) \ddagger$ & $2340(89.9) \dagger$ & \\
\hline Absent to absent & $1622(13.8) \dagger$ & 10163 (86.2)‡ & \\
\hline Physical activity & & & $<0.001^{*}$ \\
\hline Present to present & $761(8.1) \ddagger$ & $8611(91.9) \dagger$ & \\
\hline Present to absent & $456(14.5) \dagger$ & $2694(85.5) \ddagger$ & \\
\hline Absent to present & $283(9.5) \ddagger$ & $2694(90.5) \dagger$ & \\
\hline Absent to absent & $1449(13.7) \dagger$ & $9139(86.3) \ddagger$ & \\
\hline Supper time close to bedtime & & & $<0.001^{*}$ \\
\hline Absent to absent & $1998(10.8) \ddagger$ & $16551(89.2) \dagger$ & \\
\hline Absent to present & $239(11.5)$ & $1844(88.5)$ & \\
\hline Present to absent & $331(14.3) \dagger$ & $1990(85.7) \ddagger$ & \\
\hline Present to present & $381(12.2)$ & $2753(87.8)$ & \\
\hline Drinking habits & & & $0.03^{*}$ \\
\hline Absent to absent & 429 (11.9) & $3166(88.1)$ & \\
\hline Absent to present & $83(13.0)$ & $555(87.0)$ & \\
\hline Present to absent & $96(13.8) \dagger$ & 598 (86.2)‡ & \\
\hline Present to present & $2341(11.1) \ddagger$ & $18819(88.9) \dagger$ & \\
\hline Alcohol intake amount & & & $0.006^{*}$ \\
\hline Moderate to moderate & $1036(11.7)$ & 7831 (88.3) & \\
\hline
\end{tabular}




\begin{tabular}{|c|c|c|c|}
\hline \multirow[b]{3}{*}{ Variables } & \multicolumn{3}{|c|}{ Poor subjective sleep quality in 2015} \\
\hline & Present & Absent & \\
\hline & $(n=2949)$ & $(n=23138)$ & $P$ value \\
\hline Binge to moderate & $243(12.6)$ & $1687(87.4)$ & \\
\hline Binge to binge & $1443(10.7) \ddagger$ & 12050 (89.3)† & \\
\hline
\end{tabular}

Note: $n(\%)$.

*indicates statistical significance by chi-square test.

†Adjusted standardised residual $>1.96$.

$\ddagger$ Adjusted standardised residual $<-1.96$.

BMI, body mass index.

\section{Basic attributes}

These were basic information such as gender and age in 2015, and BMI, blood pressure, fasting plasma glucose and HbA1c in 2014-2015. Variables used after following classification were age (40-49, 50-59, 60-69 and 70-74 years), BMI by WHO criteria ( $<18.5$ for 'underweight'; $\geq 18.5$ and $<25$ for 'normal' and $\geq 25$ for 'overweight'), ${ }^{18}$ blood pressure status according to the American Heart Association guidelines (systolic pressure $<120$ and diastolic pressure $<80$ for 'normal'; systolic pressure 120-129 and diastolic pressure $<80$ for 'elevated'; systolic pressure 130-139 or diastolic pressure 80-89 for 'stage 1' and systolic pressure $\geq 140$ or diastolic pressure $\geq 90$ for 'stage 2' ${ }^{19}$ and presence of diabetes according to the American Diabetes Association criteria (fasting plasma glucose $\geq 126$ or HbAlc $\geq 6.5$ for 'present') ${ }^{20}$ Of these variables, we dichotomised the following three variables for statistical analysis: hypertension ('stage 1' or 'stage 2' for 'present' and 'normal' or 'elevated' for 'absent'), drinking habits ('everyday' or 'sometimes' for 'present' and 'rarely drink (cannot drink)' for 'absent') and alcohol intake amount ( $20 \mathrm{~g}$ or more for 'binge' and $<20 \mathrm{~g}$ for 'moderate').

\section{Lifestyle factors}

The habits in 2014 and 2015 of exercise, physical activity, smoking, eating meals close to bedtime and drinking (frequency and volume of alcohol intake) were assessed using the following six respective questions used in the previous studies, ${ }^{21-23}$ with yes-no response or single answers from multiple response options: for exercise, we asked 'Have you been exercising regularly for over $30 \mathrm{~min}$ at a time, during which you sweat lightly, two or more times weekly, for over a year?'; for physical activity, we asked 'In your daily life, do you walk for more than 1 hour a day or perform an equivalent amount of physical activity?'; for smoking, we asked 'Have you smoked a total of over 100 cigarettes or smoked over a period of 6 months or longer, and if so, have you been smoked in the last 1 month?'; for supper time, we asked 'Do you have an evening meal within 2 hours of going to bed, 3 times or more per week?'; for drinking frequency, we asked 'How often do you drink alcohol?' with response options of 'everyday', 'sometimes' or 'rarely drink (cannot drink)'; for alcohol intake amount, we asked 'How much do you drink per day, in terms of glasses of refined sake?', with response options of ' $<1$ glass per day', '1-2 glasses per day', '2-3 glasses per day' or ' $\geq 3$ glasses per day', using the following example sentence "'a glass $(180 \mathrm{~mL}$ ) of refined sake (rice wine) is equivalent to a medium bottle $(500 \mathrm{~mL})$ of beer, $80 \mathrm{~mL}$ of shochu (alcohol content $35 \%$ ), a glass (double, $60 \mathrm{~mL}$ ) of whiskey or two glasses $(240 \mathrm{~mL})$ of wine'. The ethanol content for each drink type was calculated to be equivalent to $20 \mathrm{~g}$.

\section{Subjective sleep quality}

In this study, SSQ was assessed using the following question with yes-no responses to briefly understand subjects' sleep depth and restfulness: 'Do you sleep well and enough?' Sleep quality was considered to be 'poor' when the subjects answered 'no'.

\section{Statistical analysis}

The characteristics of the subjects were assessed by descriptive statistics, and then further exploration was conducted using bivariate and multivariate analyses. The association between SSQ in 2015 and the change in patterns of lifestyle factors and basic attributes from 2014 to 2015 was then analysed by $\chi^{2}$ test using the following four change patterns from 2014 to 2015: for BMI (normal to normal, underweight/overweight to normal, underweight/ normal/overweight to underweight, underweight/ normal/overweight to overweight); for hypertension, diabetes, smoking, exercise, physical activity and drinking habits (absent to absent, absent to present, present to absent and present to present) and for alcohol intake amount (moderate to moderate, moderate to binge, binge to moderate and binge to binge). When statistically significant association was found in $\chi^{2}$ test, then residual analysis was conducted to clarify that category had great contribution: the cells were considered to have significantly more people than expected when the adjusted standardised residual values were greater than 1.96 and to have significantly fewer people than expected when the values were lower than 1.96. The association between SSQ in 2015 and age was examined by Mann-Whitney U test. 
To examine the association between lifestyle pattern change with SSQ by gender and to control confounders such as basic attributes, binary logistic regression analysis was employed using the referent. Subjects who had healthy status continuously from 2014 to 2015 were categorised as the referent: 'normal' for BMI; 'absent' for hypertension, diabetes, smoking, supper time close to bedtime and drinking habits; 'present' for exercise and physical activity and 'moderate' for alcohol intake amount. Explanatory variables comprised of age in 2015 and changes in patterns of lifestyle factors and basic attributes between 2014 and 2015, and response variable was poor SSQ in 2015. Three models were built in the following steps: first, one-on-one association of explanatory and response variables was created as a crude model to obtain fundamental information (model 1); second, an age-adjusted model was built (model 2); finally, a multivariate-adjusted model (model 3) was created by using all factors regardless of their significance in models 1 and 2 in logistic regression analysis. In order to test our hypothesis, a direct method was used for all models. Model 3 was selected as the final logistic regression model in the present study. The Hosmer-Lemeshow test showed the good fits in model 3 both for men and women ( $\mathrm{p}=0.977$ and 0.933 , respectively).

The variance inflation factor (VIF) was used to test multicollinearity for model 3. Among men, VIFs for age, changes in the patterns of BMI, hypertension, diabetes, smoking, exercise, physical activity, supper time, drinking habits and alcohol intake amount were 1.079, 1.033, $1.041,1.015,1.053,1.499,1.473,1.029,1.382$ and 1.414, respectively. Among women, VIFs for above-mentioned explanatory variables were $1.125,1.042,1.047,1.024$, $1.050,1.367,1.336,1.017,1.188$ and 1.232 , respectively. None of the VIF values reached 10, and the mean VIF of the model was less than 6 . Thus, there was no collinearity.

Significance level was set as 5\%, and OR and 95\% CI were calculated for gender and age, and also those in relation to the referent were calculated for other explanatory variables. All statistical analyses were performed using SPSS statistics V.25 (IBM, Armonk, New York, USA) in April 2019.

\section{Patient and public involvement}

The participants were not involved in the development of the research question, outcome measures, design, recruitment and conduct of this study.

\section{RESULTS}

As shown in table 1, the proportions of men and women were $52.7 \%$ and $47.3 \%$, respectively. In 2015 , the most common age group was the 60s $(50.0 \%)$. Both in 2014 and 2015, the most common BMI category was 'normal' $(67.1 \%$ and $66.7 \%$, respectively). The proportions of subjects who had diabetes were approximately $10 \%$ both in 2014 and 2015 (9.1\% and 10\%, respectively).
In bivariate analysis among men shown in table 2, the age was significantly lower in individuals who reported poor SSQ than those who did not $(\mathrm{p}<0.001)$. The changes in patterns of $\mathrm{BMI}$ and hypertension had significant association with poor SSQ ( $\mathrm{p}=0.003$ and 0.012 , respectively). For BMI, result of residual analysis indicated that the number of individuals with poor SSQ was significantly low in the pattern 'underweight/overweight to normal.' For lifestyle factors, the change in the patterns of smoking, exercise, physical activity, supper time, drinking habits and alcohol intake amount had statistically significant associations with poor SSQ ( $\mathrm{p}=0.027,<0.001,<0.001$, $<0.001,0.03$ and 0.006 , respectively). For supper time, the results of residual analysis indicated that poor SSQ was significantly associated to the pattern 'present to absent'.

As shown in table 3, for women, bivariate analysis indicated that age, changes in patterns of smoking, exercise, physical activity, supper time and drinking habits were significantly associated to poor SSQ ( $<0.001,0.007$, $<0.001,<0.001,<0.001$ and $<0.001$, respectively). For supper time, the results of residual analysis indicated that the numbers of individuals who reported poor SSQ were significantly high in every pattern except 'absent to absent'.

As shown in model 3 in table 4 for men, of basic attributes, statistically significant associations were found between poor SSQ and age (OR=0.990; 95\% CI 0.985 to 0.996) and the change in patterns of BMI 'underweight/ normal/overweight to underweight' ( $\mathrm{OR}=1.305 ; 95 \%$ CI 1.047 to 1.625$)$. Of lifestyle pattern changes, significant associations with poor SSQ were found in 'present to absent' (OR=1.469; 95\% CI 1.273 to 1.695$)$, 'absent to present' ( $\mathrm{OR}=1.211 ; 95 \%$ CI 1.038 to 1.411$)$ and 'absent to absent' (OR=1.472; 95\% CI 1.316 to 1.647$)$ for exercise, 'present to absent' (OR=1.620; 95\% CI 1.421 to 1.847$)$ and 'absent to absent' (OR=1.420; 95\% CI 1.270 to 1.588$)$ for physical activity and 'present to absent' $(\mathrm{OR}=1.374 ; 95 \%$ CI to $1.210,1.560)$ and 'present to present' (OR=1.149; 95\% CI 1.020 to 1.294) for supper time close to bedtime.

As shown in model 3 in table 5 for women, significantly high ORs compared with the referent were found in the category 'present to absent' (OR=1.563; 95\% CI 1.352 to $1.807)$ and 'absent to absent' ( $\mathrm{OR}=1.428$; 95\% CI 1.285 to 1.587) for exercise, 'present to absent' ( $\mathrm{OR}=1.416$; $95 \%$ CI 1.236 to 1.620$)$ and 'absent to absent' ( $\mathrm{OR}=1.471$; 95\% CI 1.322 to 1.638 ) for physical activity, 'absent to present' (OR=1.254; 95\% CI 1.068 to 1.472$)$, 'present to absent' (OR=1.250; 95\% CI 1.069 to 1.461$)$ and 'present to present' ( $\mathrm{OR}=1.288 ; 95 \%$ CI 1.102 to 1.505$)$ for supper time close to bedtime and 'absent to present' $(\mathrm{OR}=1.386$; 95\% CI 1.176 to 1.635 ) for drinking habits. Smoking habits did not significantly associate to SSQ.

\section{DISCUSSION}

This study was conducted to examine the association between lifestyle pattern changes and poor SSQ. We discovered that poor SSQ was significantly associated to 
Table 3 Associations of basic attribute and lifestyle transition with poor subjective sleep quality in 2015 among women

Poor subjective sleep quality in 2015

Present

(n=3120)

$67(62-71)$

Absent
$(n=20276)$

$68(64-71)$
Variables

Age (years), median (25-75 percentile)

\section{P value} $<0.001^{*}$

0.318

BMI

Normal to normal

Underweight/overweight to normal

Underweight/normal/overweight to underweight

Underweight/normal/overweight to overweight

Hypertension

Absent to absent

Absent to present

Present to absent

Present to present

Diabetes

Absent to absent

Absent to present

Present to absent

Present to present

Smoking

Absent to absent

Absent to present

Present to absent

Present to present

Exercise

Present to present

Present to absent

Absent to present

Absent to absent

Physical activity

Present to present

Present to absent

Absent to present

Absent to absent

Supper time close to bedtime

Absent to absent

Absent to present

Present to absent

Present to present

Drinking habits

Absent to absent

Absent to present

Present to absent

Present to present

Alcohol intake amount
1981 (13.1)

118 (13.5)

247 (14.6)

774 (13.6)

$1083(14.0)$

475 (13.7)

$430(13.1)$

$1132(12.7)$

2896 (13.4)

46 (11.5)

41 (14.6)

$137(11.9)$

2934 (13.2)‡

15 (19.0)

17 (15.3)

154 (16.7)†

729 (9.4)‡

325 (15.7)†

248 (11.4)‡

1818 (15.9)†

$699(9.5) \ddagger$

408 (14.7)†

318 (11.4)‡

1695 (16.2)†

2507 (12.8)†

194 (15.5)†

206 (15.8)†

213 (16.8)†

1461 (12.9)†

197 (17.3)†

153 (12.8)

1309 (13.5)
13158 (86.9)

756 (86.5)

1445 (85.4)

4917 (86.4)

6660 (86.0)

2981 (86.3)

2863 (86.9)

7772 (87.3)

0.28

18668 (86.6)

355 (88.5)

239 (85.4)

1014 (88.1)

$0.007^{*}$

$19348(86.8) \dagger$

64 (81.0)

94 (84.7)

770 (83.3)†

0.088

7016 (90.6)†

1750 (84.3)‡

1927 (88.6)†

9583 (84.1)‡

$<0.001^{*}$

6643 (90.5)†

2374 (85.3)‡

2461 (88.6)†

8798 (83.8)†

$<0.001^{*}$

$<0.001^{*}$

17063 (87.2)†

1059 (84.5)‡

1101 (84.2)‡

1053 (83.2)‡

$<0.001^{*}$

9875 (87.1)†

940 (82.7)†

1045 (87.2)

8416 (86.5) 


\begin{tabular}{|c|c|c|c|}
\hline \multirow[b]{3}{*}{ Variables } & \multicolumn{3}{|c|}{ Poor subjective sleep quality in 2015} \\
\hline & Present & Absent & \\
\hline & $(n=3120)$ & $(n=20276)$ & $P$ value \\
\hline Moderate to binge & $121(13.9)$ & $748(86.1)$ & \\
\hline Binge to moderate & $133(14.7)$ & $773(85.3)$ & \\
\hline
\end{tabular}

Note: $n$ (\%).

*indicates statistical significance by chi-square test.

†Adjusted standardised residual $>1.96$.

$\ddagger$ Adjusted standardised residual $<-1.96$.

BMI, body mass index.

the change in lifestyle patterns of exercise, physical activity and supper time both in men and women; in addition, reduction of BMI for men and presence of drinking habits for women were gender-specific factors associated to poor SSQ. The findings of the present study may contribute to the enhancement of SSQ, since the improvement of lifestyle patterns may be practically approached.

The proportions of men and women were similar, median age was 68 and the most common age group was the $60 \mathrm{~s}$. For BMI, the 'normal' was the most common category. The number of subjects with diabetes was small. For the interpretation of these results, it is necessary to discuss the association of potential confounders with Poor SSQ. Although several health problems such as sleep apnoea, depression and suicide are associated to poor $\mathrm{SSQ}^{3-5}$ and thus are considered to be potential confounders, the present study did not measure these health problems. Therefore, our results could not provide the data for precise interpretation. However, in light of past studies that reported that ageing is risk factor of sleep apnoea, ${ }^{24}$ whereas prevalence of mood disorder including depression among Japanese was higher in individuals aged 20-64 years old than those aged 65 or older, ${ }^{25}$ the study subjects may have both healthy and unhealthy attributions related to poor SSQ taking their median age and common age group into account.

Our bivariate analysis showed that age of individuals with poor SSQ was significantly lower than those without poor SSQ both among men and women, while past studies reported that poor SSQ is associated with ageing and is prevalent among the older population. ${ }^{26}$ Importantly, the difference of median age between individuals with and without poor SSQ was just a year, and thus there is few practical/clinical suggestion even though statistical difference was found. Association of age and changes in the patterns of lifestyle such as exercise, physical activity and supper time to poor SSQ presence require further investigation via multivariate analysis.

In multivariate analysis, results are discussed in detail using four patterns of lifestyle change, including healthy/unhealthy lifestyle change and keeping healthy/ unhealthy lifestyle that we defined.

Among men, the results of logistic regression analysis indicated that the unhealthy change of BMI 'underweight/normal/overweight to underweight' was significantly associated to poor SSQ. Past studies indicated that high BMI/obesity is associated to sleep problems such as sleep apnoea, short sleep duration, low sleep quality, less efficiency, daytime sleepiness and inadequate timing of sleep, ${ }^{27} 28$ and these sleep problems are considered to be components of low SSQ. The results of our study were inconsistent with such past studies, and thus the presence of unexpected confounding factor is of suspected. Importantly, mental health problem such as depression is associated to both weight loss and sleep problem. ${ }^{49}$ The change to 'underweight' may be actually associated to such mental health problem, not to SSQ.

For exercise among men, ORs were significantly higher in all patterns than in the referent. The pattern 'absent to present', which was theoretically considered to be healthy lifestyle change, was rather associated to poor SSQ, and thus this result is not consistent with the hypothesis. It is important that the healthy change pattern 'absent to present' had lower OR than those of unhealthy lifestyle change and keeping unhealthy lifestyle. Subjects in 'absent to present' might be in the middle of improving direction of SSQ, but not fully achieved such improvement. This interpretation brings practical suggestion that the engagement in exercise at least for 2 years may contribute to improved SSQ.

The results regarding physical activity among men were consistent with our hypothesis: unhealthy lifestyle change and keeping unhealthy lifestyle were associated to poor SSQ. Although it is impossible to discuss the causal relationships between physical activity and SSQ due to the research design, the results indicated that continuation of physical activity for at least 1 year may be equivalent to 2 years of continuation. Considering that physical activity is defined as any bodily movement ${ }^{30}$ and was defined as engagement in walking or equivalent physical activity in 
Table 4 Logistic regression models of association between lifestyle transition and poor subjective sleep quality among men ORs $(95 \% \mathrm{Cl})$

\begin{tabular}{llll} 
Variables & Model 1 & Model 2 & Model 3 \\
\hline Age & $0.881(0.839 \text { to } 0.925)^{*}$ & N/A $†$ & $0.990(0.985$ to 0.996)
\end{tabular}

BMl change

Normal to normal $\quad$ ref. $\quad$ ref.

Underweight/overweight to normal

0.786 (0.626 to 0.986$)^{\star} \quad 0.784(0.625 \text { to } 0.984)^{\star} \quad 0.773(0.615 \text { to } 0.972)^{\star}$

Underweight/normal/overweight to underweight $1.385(1.115 \text { to } 1.722)^{\star} \quad 1.373(1.105 \text { to } 1.707)^{\star} \quad 1.305(1.047 \text { to } 1.625)^{\star}$

Underweight/normal/overweight to overweight $\quad 0.979$ (0.901 to 1.064) $\quad 0.969$ (0.892 to 1.054) 0.943 (0.866 to 1.028)

Hypertension

Absent to absent

ref.

ref.

ref.

Absent to present

1.021 (0.899 to 1.159$) \quad 1.033$ (0.909 to 1.173$)$

1.035 (0.910 to 1.178$)$

Present to absent

1.051 (0.926 to 1.192$) \quad 1.066$ (0.940 to 1.210$)$

1.085 (0.954 to 1.233$)$

Present to present

0.899 (0.815 to 0.992$)^{\star} \quad 0.914$ (0.828 to 1.008$)$

0.934 (0.844 to 1.034)

Diabetes

\begin{tabular}{|c|c|c|c|}
\hline Absent to absent & ref. & ref. & ref. \\
\hline Absent to present & 0.936 (0.757 to 1.158$)$ & 0.958 (0.774 to 1.185$)$ & 0.995 (0.803 to 1.234$)$ \\
\hline Present to absent & 0.995 (0.776 to 1.276$)$ & 1.019 (0.794 to 1.308$)$ & $1.030(0.801$ to 1.324$)$ \\
\hline Present to present & 0.900 (0.785 to 1.031$)$ & 0.921 (0.804 to 1.055$)$ & 0.927 (0.808 to 1.064$)$ \\
\hline \multicolumn{4}{|l|}{ Smoking } \\
\hline Absent to absent & ref. & ref. & ref. \\
\hline Absent to present & 0.918 (0.606 to 1.392$)$ & 0.918 (0.606 to 1.393$)$ & 0.878 (0.578 to 1.336$)$ \\
\hline Present to absent & 1.446 (1.111 to 1.883$)^{*}$ & 1.429 (1.097 to 1.861$) \ddagger$ & 1.351 (1.035 to 1.764$) \ddagger$ \\
\hline Present to present & 1.066 (0.972 to 1.170$)$ & 1.030 (0.938 to 1.131$)$ & 0.957 (0.870 to 1.054$)$ \\
\hline \multicolumn{4}{|l|}{ Exercise } \\
\hline Present to present & ref. & ref. & ref. \\
\hline Present to absent & 1.759 (1.534 to 2.016$)^{*}$ & $1.748(1.525 \text { to } 2.004)^{*}$ & $1.469(1.273 \text { to } 1.695)^{\star}$ \\
\hline Absent to present & $1.313(1.132 \text { to } 1.522)^{*}$ & $1.302(1.122 \text { to } 1.510)^{*}$ & $1.211(1.038 \text { to } 1.411)^{*}$ \\
\hline Absent to absent & $1.857(1.693 \text { to } 2.037)^{*}$ & $1.816(1.653 \text { to } 1.994)^{*}$ & $1.472(1.316 \text { to } 1.647)^{\star}$ \\
\hline \multicolumn{4}{|l|}{ Physical activity } \\
\hline Present to present & ref. & ref. & ref. \\
\hline Present to absent & $1.915(1.692 \text { to } 2.168)^{*}$ & $1.897(1.676 \text { to } 2.148)^{*}$ & $1.620(1.421 \text { to } 1.847)^{*}$ \\
\hline Absent to present & $1.189(1.030 \text { to } 1.372)^{*}$ & $1.175(1.018 \text { to } 1.356)^{*}$ & $1.043(0.898$ to 1.211$)$ \\
\hline Absent to absent & $1.794(1.635 \text { to } 1.968)^{*}$ & $1.755(1.598 \text { to } 1.927)^{*}$ & $1.420(1.270 \text { to } 1.588)^{*}$ \\
\hline \multicolumn{4}{|c|}{ Supper time close to bedtime } \\
\hline Absent to absent & ref. & ref. & ref. \\
\hline Absent to present & 1.074 (0.931 to 1.238$)$ & 1.075 (0.932 to 1.239$)$ & 1.070 (0.927 to 1.236$)$ \\
\hline Present to absent & $1.378(1.216 \text { to } 1.562)^{*}$ & $1.383(1.220 \text { to } 1.567)^{*}$ & $1.374(1.210 \text { to } 1.560)^{*}$ \\
\hline Present to present & $1.146(1.020 \text { to } 1.288)^{*}$ & $1.130(1.005 \text { to } 1.270)^{*}$ & $1.149(1.020 \text { to } 1.294)^{*}$ \\
\hline \multicolumn{4}{|l|}{ Drinking habits } \\
\hline Absent to absent & ref. & ref. & ref. \\
\hline Absent to present & 1.104 (0.858 to 1.420$)$ & 1.105 (0.859 to 1.421$)$ & 1.067 (0.826 to 1.377$)$ \\
\hline Present to absent & 1.185 (0.934 to 1.503$)$ & 1.189 (0.937 to 1.508$)$ & 1.179 (0.925 to 1.502$)$ \\
\hline Present to present & 0.918 (0.823 to 1.024$)$ & 0.925 (0.829 to 1.033$)$ & 0.973 (0.854 to 1.108$)$ \\
\hline \multicolumn{4}{|l|}{ Alcohol intake amount } \\
\hline Moderate to moderate & ref. & ref. & ref. \\
\hline Moderate to binge & 1.093 (0.937 to 1.274$)$ & 1.088 (0.933 to 1.269$)$ & 1.097 (0.934 to 1.287$)$ \\
\hline
\end{tabular}

Continued 


\begin{tabular}{|c|c|c|c|}
\hline \multirow[b]{2}{*}{ Variables } & \multicolumn{3}{|l|}{ ORs $(95 \% \mathrm{Cl})$} \\
\hline & Model 1 & Model 2 & Model 3 \\
\hline Binge to moderate & $1.089(0.938$ to 1.264$)$ & $1.093(0.942$ to 1.269$)$ & $1.078(0.922$ to 1.261$)$ \\
\hline
\end{tabular}

*Indicates statistical significance for age, or statistical significance between referent and category when the variable has the referent, by logistic regression. The following three models were created and presented: crude model (model 1), age-adjusted model (model 2 ) and multivariate-adjusted model (model 3).

$\dagger N / A$ indicates 'not applicable', because age was input consistently in model 2 and thus their ORs and $95 \% \mathrm{Cl}$ were omitted. $\ddagger$ Statistical significance in this category was not discussed, because no statistical significance was found in the corresponding referent. BMI, body mass index.

this study, the habit of physical activity may be practical for SSQ improvement since physical activity can be more easily incorporated into daily life than exercise.

For supper time close to bedtime among men, significant associations were found in 'present to absent' and 'present to present' compared with the referent, and these results represented that poor SSQ was statistically prevalent in the subjects both who had healthy lifestyle change and kept unhealthy lifestyle. These facts seem like a contradiction and thus should be interpreted carefully. Past studies reported that meals within 3 hours of bedtime are positively associated with nocturnal awakening, ${ }^{13}$ and that nocturnal awakening is associated to daytime sleepiness. ${ }^{31}$ In light of these past studies, subjects in the patterns of 'present to absent' and 'present to present' may have had daytime sleepiness in 2014 due to lifestyle of supper close to bedtime, such daytime sleepiness may have lasted and thus they reported their poor SSQ in 2015. Although there is a possibility that the perception of reduced SSQ motivated the improved lifestyle regarding supper time, our interpretation that association between supper time close to bedtime and sleep problem in previous year may carry over into following year may have practical implication for improvement of SSQ.

For exercise and physical activity among women, the results were consistent with our hypothesis: unhealthy lifestyle change and keeping unhealthy lifestyle were associated to poor SSQ. The OR of 'absent to present' category of exercise did not have statistical significance, compared with the referent, whereas that among men had statistical significance. Among women, the engagement in exercise and physical activity in a certain year may have an equivalent effect to continuation of them, or the absence of poor SSQ may contribute to the presence of exercise and physical activity.

For supper time close to bedtime, the pattern 'present to absent', the healthy lifestyle change, was associated to poor SSQ contrary to our hypothesis. This result does not necessarily mean that women should avoid the healthy lifestyle change in order to improve their SSQ because continuous absence of supper time close to bedtime is possibly associated to good, or moderate SSQ as we showed in the referent defined as 2 years of continuation of absence of such lifestyle. Subjects in the pattern 'present to absent' may have the improved SSQ when they keep healthy lifestyle for supper time, that is, they may be in the middle of improvement process. For drinking habits, the results were partially consistent with our hypothesis since poor SSQ was statistically prevalent only when subjects were in the pattern "absent to present," unhealthy lifestyle change. Whereas, it is important to note that no association was found between SSQ and the pattern 'present to present', defined as keeping unhealthy lifestyle. There may be a difference of background between subjects who started unhealthy lifestyle and those who kept it. Past study indicated that women more precisely recognise their sleep problems and thus more actively manage to such problems than men. ${ }^{32}$ In light of this past study, it is assumed that women subjects in the pattern "present to present'may have carefully self-monitored regarding their drinking habits, and thus the degree of such habits may have been controllable or manageable; poor SSQ may not have been prevalent even if they had drinking habits.

Although we hypothesised that poor SSQ is associated to starting/continuing smoking, this hypothesis was rejected, whereas past studies indicated that smoking habit was associated with low-quality sleep, ${ }^{33}$ our results suggest the possibility that poor SSQ may not be explained by smoking. Although our results did not reveal the causeand-effect link between lifestyle change and SSQ it may have practical suggestion: the focus on the improvement of exercise, physical activity and supper time both for men and women, rather than smoking, may contribute to the solution of poor SSQ.

In regards to the generalisability of present study, this study had following two potential biases. First, the subjects were extracted from database of National Health Insurance Organisation. The consumer of National Health Insurance Organisation was commonly comprised of individuals who were in self-employed, retired or non-standard employment. ${ }^{34}$ It is assumed that there are gaps between our study subjects and Japanese and also global population. Second, the results of present study might be influenced by the Great East Japan Earthquake in 2011, since the study subjects comprised of individuals who lived in Fukushima Prefecture, Japan, in 2014-2015. Past studies reported psychiatric sequelae such as insomnia, anxiety, depression 
Table 5 Logistic regression models of association between lifestyle transition and poor subjective sleep quality among women

\begin{tabular}{|c|c|c|c|}
\hline \multirow[b]{2}{*}{ Variables } & \multicolumn{3}{|l|}{ ORs $(95 \% \mathrm{Cl})$} \\
\hline & Model 1 & Model 2 & Model 3 \\
\hline Age & $0.826(0.787 \text { to } 0.868)^{*}$ & N/A $\dagger$ & $0.983(0.978 \text { to } 0.989)^{*}$ \\
\hline \multicolumn{4}{|l|}{ BMI change } \\
\hline Normal to normal & ref. & ref. & ref. \\
\hline Underweight/overweight to normal & 1.037 (0.849 to 1.266$)$ & $1.037(0.849$ to 1.267$)$ & 1.025 (0.838 to 1.254$)$ \\
\hline Underweight/normal/overweight to underweight & 1.135 (0.984 to 1.310$)$ & 1.109 (0.961 to 1.280$)$ & $1.082(0.936$ to 1.251$)$ \\
\hline Underweight/normal/overweight to overweight & 1.046 (0.956 to 1.143$)$ & 1.048 (0.958 to 1.146$)$ & 0.999 (0.911 to 1.096$)$ \\
\hline \multicolumn{4}{|l|}{ Hypertension } \\
\hline Absent to absent & ref. & ref. & ref. \\
\hline Absent to present & 0.980 (0.872 to 1.101$)$ & 1.031 (0.917 to 1.159$)$ & $1.022(0.908$ to 1.150$)$ \\
\hline Present to absent & 0.924 (0.819 to 1.041$)$ & 0.978 (0.867 to 1.104$)$ & 0.970 (0.858 to 1.096$)$ \\
\hline Present to present & $0.896(0.819$ to 0.980$) \neq$ & 0.957 (0.874 to 1.049$)$ & 0.960 (0.875 to 1.054$)$ \\
\hline \multicolumn{4}{|l|}{ Diabetes } \\
\hline Absent to absent & ref. & ref. & ref. \\
\hline Absent to present & 0.835 (0.613 to 1.138$)$ & 0.875 (0.642 to 1.193$)$ & 0.883 (0.646 to 1.207$)$ \\
\hline Present to absent & $1.106(0.792$ to 1.544$)$ & $1.160(0.831$ to 1.621$)$ & $1.184(0.845$ to 1.659$)$ \\
\hline Present to present & 0.871 (0.726 to 1.045$)$ & 0.912 (0.759 to 1.095$)$ & 0.912 (0.757 to 1.098$)$ \\
\hline \multicolumn{4}{|l|}{ Smoking } \\
\hline Absent to absent & ref. & ref. & ref. \\
\hline Absent to present & $1.546(0.880$ to 2.715$)$ & 1.478 (0.840 to 2.599$)$ & 1.404 (0.794 to 2.482$)$ \\
\hline Present to absent & 1.193 (0.710 to 2.002$)$ & 1.140 (0.678 to 1.915$)$ & 1.084 (0.642 to 1.830$)$ \\
\hline Present to present & $1.319(1.105 \text { to } 1.575)^{\star}$ & $1.212(1.013$ to 1.449$) \ddagger$ & 1.153 (0.959 to 1.386$)$ \\
\hline \multicolumn{4}{|l|}{ Exercise } \\
\hline Present to present & ref. & ref. & ref. \\
\hline Present to absent & $1.787(1.553 \text { to } 2.058)^{\star}$ & $1.769(1.537 \text { to } 2.037)^{\star}$ & $1.563(1.352 \text { to } 1.807)^{\star}$ \\
\hline Absent to present & $1.239(1.063 \text { to } 1.443)^{*}$ & $1.221(1.048 \text { to } 1.423)^{*}$ & 1.127 (0.964 to 1.318$)$ \\
\hline Absent to absent & $1.826(1.667 \text { to } 2.000)^{*}$ & $1.747(1.593 \text { to } 1.917)^{\star}$ & $1.428(1.285 \text { to } 1.587)^{\star}$ \\
\hline \multicolumn{4}{|l|}{ Physical activity } \\
\hline Present to present & ref. & ref. & ref. \\
\hline Present to absent & $1.633(1.433 \text { to } 1.862)^{\star}$ & $1.619(1.420 \text { to } 1.846)^{*}$ & $1.416(1.236 \text { to } 1.620)^{*}$ \\
\hline Absent to present & $1.228(1.067 \text { to } 1.413)^{\star}$ & $1.209(1.050 \text { to } 1.391)^{\star}$ & 1.099 (0.951 to 1.271$)$ \\
\hline Absent to absent & $1.831(1.667 \text { to } 2.011)^{\star}$ & $1.765(1.606 \text { to } 1.940)^{*}$ & $1.471(1.322 \text { to } 1.638)^{*}$ \\
\hline \multicolumn{4}{|l|}{ Supper time close to bedtime } \\
\hline Absent to absent & ref. & ref. & ref. \\
\hline Absent to present & $1.247(1.064 \text { to } 1.461)^{\star}$ & $1.255(1.071 \text { to } 1.471)^{\star}$ & $1.254(1.068 \text { to } 1.472)^{\star}$ \\
\hline Present to absent & $1.273(1.091 \text { to } 1.486)^{\star}$ & $1.280(1.096 \text { to } 1.494)^{*}$ & $1.250(1.069 \text { to } 1.461)^{\star}$ \\
\hline Present to present & $1.377(1.181 \text { to } 1.605)^{\star}$ & $1.327(1.138 \text { to } 1.548)^{\star}$ & $1.288(1.102 \text { to } 1.505)^{\star}$ \\
\hline \multicolumn{4}{|l|}{ Drinking habits } \\
\hline Absent to absent & ref. & ref. & ref. \\
\hline Absent to present & $1.417(1.203 \text { to } 1.667)^{\star}$ & $1.405(1.193 \text { to } 1.654)^{\star}$ & $1.386(1.176 \text { to } 1.635)^{\star}$ \\
\hline Present to absent & 0.990 (0.828 to 1.183$)$ & 0.977 (0.817 to 1.168$)$ & 0.957 (0.799 to 1.145$)$ \\
\hline Present to present & 1.051 (0.970 to 1.139$)$ & 1.017 (0.938 to 1.102$)$ & 1.030 (0.942 to 1.125$)$ \\
\hline \multicolumn{4}{|l|}{ Alcohol intake amount } \\
\hline Moderate to moderate & ref. & ref. & ref. \\
\hline
\end{tabular}




\begin{tabular}{|c|c|c|c|}
\hline \multirow[b]{2}{*}{ Variables } & \multicolumn{3}{|l|}{ ORs $(95 \% \mathrm{Cl})$} \\
\hline & Model 1 & Model 2 & Model 3 \\
\hline Moderate to binge & $1.062(0.872$ to 1.292$)$ & 1.009 (0.828 to 1.229$)$ & $0.989(0.807$ to 1.211$)$ \\
\hline Binge to binge & 1.037 (0.898 to 1.198$)$ & 0.931 (0.804 to 1.078$)$ & $0.900(0.767$ to 1.055$)$ \\
\hline
\end{tabular}

*Indicates statistical significance for age, or statistical significance between referent and category when the variable has the referent, by logistic regression. The following three models were created and presented: crude model (model 1), age-adjusted model (model 2) and multivariate-adjusted model (model 3).

†N/A indicates 'not applicable', because age was input consistently in model 2 and thus their ORs and $95 \% \mathrm{Cl}$ were omitted. ¥Statistical significance in this category was not discussed, because no statistical significance was found in the corresponding referent. BMI, body mass index.

and alcohol misuse after the disaster. ${ }^{35-37}$ These psychiatric sequelae may be associated to lifestyle change and SSQ. It cannot be denied the possibility that the subjects in present study were under the long-term effects of such psychiatric sequelae, whereas, it is reasonable to say that our study subjects might include the individuals who did not experience the disaster since the large sample size, approximately 50000 . This possible variety of sampling might contribute to the reduction of bias in the present study. Therefore, we believe that our study could present a useful result in line with the study purpose.

The present study has the following four limitations. First, we could not measure the duration of lifestyle habits. The responses from the subjects were collected via annual health check-ups, and thus the answers in each year may have not reflected the actual duration of the habits in question. Second, data based on the subjects' experiences in their social lives that were possibly associated to SSQ were not collected. For example, a previous study indicated that job stress is associated with low-quality sleep. ${ }^{38}$ Future studies should collect information related to social life such as job stress, domestic trouble and financial problems. Third, the present study had flaws in adjustment of potential confounder such as musculoskeletal pain, depression and insomnia and in outcome measurement. In regards to adjustment of potential confounder, the integrative analysis using broader medical records in addition data of medical check-ups may be a solution. Finally, the data were collected cross-sectionally, and thus cause-and-effect relationship between lifestyle change and SSQ was not pursuable. It is required that future study should employ more elaborated research design such as cohort to provide robust evidence regarding the association between lifestyle change and SSQ than current study.

\section{CONCLUSION}

Poor SSQ was observed in men who did not engage in exercise continuously over 2 years, did not engage in physical activity at the given year and had a supper time within 2 hours before bedtime in previous year, and in females who did not engage in exercise and physical activity at the given year, had a supper time within 2 hours before bedtime over 2 years and started the drinking habits in the given year. In public health, sleep quality is emphasised not only for prevention of other health problems but also as an important health outcome. Healthcare workers may be able to contribute to the prevention of poor SSQ, focusing on the improvements of changeable lifestyle habits, such as exercise, physical activity and supper time both for men and women, and as drinking habits for women.

Acknowledgements We are grateful to NHIO for their assistance with data acquisition.

Contributors $\mathrm{TH}$ created the study concept and design, analysed and interpreted the data, drafted the initial manuscript and critically revised the manuscript for important intellectual content. HK, SE, YM and TK provided technical support and critically revised the manuscript for important intellectual content. AT and MK collected the data. TF provided administrative support, acquired and interpreted the data and critically revised the manuscript for important intellectual content.

Funding The authors have not declared a specific grant for this research from any funding agency in the public, commercial or not-for-profit sectors.

Competing interests None declared.

Patient and public involvement Patients and/or the public were not involved in the design, or conduct, or reporting, or dissemination plans of this research.

Patient consent for publication Not required.

Ethics approval The study protocol was approved by the Ethics Committee of Fukushima Medical University, Fukushima, Japan (Application No. 2974).

Provenance and peer review Not commissioned; externally peer reviewed.

Data availability statement Data are available in a public, open access repository. Extra data can be accessed via the Dryad data repository at http://datadryad.org/ with the doi:10.5061/dryad.31zcrjdjn

Open access This is an open access article distributed in accordance with the Creative Commons Attribution Non Commercial (CC BY-NC 4.0) license, which permits others to distribute, remix, adapt, build upon this work non-commercially, and license their derivative works on different terms, provided the original work is properly cited, appropriate credit is given, any changes made indicated, and the use is non-commercial. See: http://creativecommons.org/licenses/by-nc/4.0/.

\section{ORCID iDs}

Tomoo Hidaka http://orcid.org/0000-0003-2987-4804

Hideaki Kasuga http://orcid.org/0000-0002-4761-0813

Takeyasu Kakamu http://orcid.org/0000-0001-6920-8457

\section{REFERENCES}

1 Kline C. Sleep quality. In: Gellman MD, Turner JR, eds. Encyclopedia of behavioral medicine. New York: Springer, 2013: 1811-3. 
2 Kaplan KA, Hirshman J, Hernandez B, et al. When a gold standard isn't so golden: Lack of prediction of subjective sleep quality from sleep polysomnography. Biol Psychol 2017;123:37-46.

3 MN W, Lai CL, Liu CK, et al. More severe hypoxemia is associated with better subjective sleep quality in obstructive sleep apnea. BMC Pulm Med 2015;15:117

4 De Gennaro L, Martina M, Curcio G, et al. The relationship between alexithymia, depression, and sleep complaints. Psychiatry Res 2004;128:253-8.

5 Bernert RA, Turvey CL, Conwell Y, et al. Association of poor subjective sleep quality with risk for death by suicide during a 10year period: a longitudinal, population-based study of late life. JAMA Psychiatry 2014;71:1129-37.

6 Resta O, Foschino Barbaro MP, Bonfitto P, et al. Low sleep quality and daytime sleepiness in obese patients without obstructive sleep apnoea syndrome. J Intern Med 2003;253:536-43.

7 Cappuccio FP, Cooper D, D'Elia L, et al. Sleep duration predicts cardiovascular outcomes: a systematic review and meta-analysis of prospective studies. Eur Heart J 2011;32:1484-92.

8 Foley KA, Sarsour K, Kalsekar A, et al. Subtypes of sleep disturbance: associations among symptoms, comorbidities, treatment, and medical costs. Behav Sleep Med 2010;8:90-104.

9 Singh NA, Clements KM, Fiatarone MA. A randomized controlled trial of the effect of exercise on sleep. Sleep 1997;20:95-101.

10 Benloucif S, Orbeta L, Ortiz R, et al. Morning or evening activity improves neuropsychological performance and subjective sleep quality in older adults. Sleep 2004;27:1542-51.

11 Wetter DW, Young TB. The relation between cigarette smoking and sleep disturbance. Prev Med 1994;23:328-34.

12 Devenney LE, Coyle KB, Roth T, et al. Sleep after heavy alcohol consumption and physical activity levels during alcohol hangover. $J$ Clin Med 2019;8:752.

13 Chung N, Bin YS, Cistulli PA, et al. Does the proximity of meals to bedtime influence the sleep of young adults? A cross-sectional survey of university students. Int J Environ Res Public Health 2020;17:2677.

14 Merrill RM, Aldana SG, Greenlaw RL, et al. The effects of an intensive lifestyle modification program on sleep and stress disorders. J Nutr Health Aging 2007;11:242-8.

15 Kline CE, Crowley EP, Ewing GB, et al. The effect of exercise training on obstructive sleep apnea and sleep quality: a randomized controlled trial. Sleep 2011;34:1631-40.

16 Bellatorre A, Choi K, Lewin D, et al. Relationships between smoking and sleep problems in black and white adolescents. Sleep 2017;40. doi:10.1093/sleep/zsw031. [Epub ahead of print: 01 Jan 2017].

17 Yahia N, Brown C, Potter S, et al. Night eating syndrome and its association with weight status, physical activity, eating habits, smoking status, and sleep patterns among college students. Eat Weight Disord 2017;22:421-33.

18 World Health Organization. Obesity: preventing and managing the global epidemic - report of a who consultation (who technical report series 894). Geneva, 2000.

19 Whelton PK, Carey RM, Aronow WS, et al. 2017 ACC/AHA/AAPA ABC/ACPM/AGS/APhA/ASH/ASPC/NMA/PCNA guideline for the prevention, detection, evaluation, and management of high blood pressure in adults: a report of the American College of Cardiology/ American heart association Task force on clinical practice guidelines. J Am Coll Cardiol 2018;71:e127-248.
20 American Diabetes Association. 2. Classification and Diagnosis of Diabetes: Standards of Medical Care in Diabetes-2019. Diabetes Care 2019;42:S13-28.

21 Hidaka $\mathrm{T}$, Endo $\mathrm{S}$, Kasuga $\mathrm{H}$, et al. Associations of presence or absence of exercise and/or physical activity with non-restorative sleep by gender and age: a cross-sectional study. BMJ Open 2019;9:e025730.

22 Wakasugi M, Kazama JJ, Narita I, et al. Association between combined lifestyle factors and non-restorative sleep in Japan: a cross-sectional study based on a Japanese health database. PLoS One 2014;9:e108718.

23 Matsumoto T, Tabara Y, Murase K, et al. Combined association of clinical and lifestyle factors with non-restorative sleep: the Nagahama study. PLoS One 2017;12:e0171849.

24 Young T, Shahar E, Nieto FJ, et al. Predictors of sleep-disordered breathing in community-dwelling adults: the sleep heart health study. Arch Intern Med 2002;162:893-900.

25 Ishikawa $\mathrm{H}$, Tachimori $\mathrm{H}$, Takeshima $\mathrm{T}$, et al. Prevalence, treatment, and the correlates of common mental disorders in the mid 2010's in Japan: the results of the world mental health Japan 2nd survey. $J$ Affect Disord 2018;241:554-62.

26 Castro CM, Lee KA, Bliwise DL, et al. Sleep patterns and sleeprelated factors between caregiving and non-caregiving women. Behav Sleep Med 2009;7:164-79.

27 Young T, Palta M, Dempsey J, et al. The occurrence of sleepdisordered breathing among middle-aged adults. N Engl J Med 1993;328:1230-5.

28 Ogilvie RP, Patel SR. The epidemiology of sleep and obesity. Sleep Health 2017;3:383-8.

29 Chaitoff A, Swetlik C, Ituarte C, et al. Associations between unhealthy weight-loss strategies and depressive symptoms. Am J Prev Med 2019;56:241-50.

30 World Health Organization. Physical activity. 2019. Available: http:// www.who.int/dietphysicalactivity/pa/en/ [Accessed April 2, 2019].

$31 \mathrm{Li} \mathrm{J}$, Cacchione PZ, Hodgson N, et al. Afternoon napping and cognition in Chinese older adults: findings from the China health and retirement longitudinal study baseline assessment. J Am Geriatr Soc 2017;65:373-80.

32 Sidani S, Guruge S, Fox M, et al. Gender differences in perpetuating factors, experience and management of chronic insomnia. $J$ Gend Stud 2019;28:402-13.

33 Phillips BA, Danner FJ. Cigarette smoking and sleep disturbance. Arch Intern Med 1995;155:734-7.

34 Sakamoto H, Rahman M, Nomura S, et al. Japan health system review. health systems in transition (World Health organization, regional office for south-east Asia. New Delhi, 2018.

35 Kukihara H, Yamawaki N, Uchiyama K, et al. Trauma, depression, and resilience of earthquake/tsunami/nuclear disaster survivors of Hirono, Fukushima, Japan. Psychiatry Clin Neurosci 2014;68:524-33.

36 Karz A, Reichstein J, Yanagisawa R, et al. Ongoing mental health concerns in post-3/11 Japan. Ann Glob Health 2014;80:108-14.

37 Takebayashi Y, Lyamzina Y, Suzuki Y, et al. Risk perception and anxiety regarding radiation after the 2011 Fukushima nuclear power plant accident: a systematic qualitative review. Int J Environ Res Public Health 2017;14:1306.

38 Knudsen HK, Ducharme LJ, Roman PM. Job stress and poor sleep quality: data from an American sample of full-time workers. Soc Sci Med 2007;64:1997-2007. 